\title{
Scabies in displaced families: Health care problem that need urgent action
}

\author{
Abdulghani Mohamed Alsamarai ${ }^{1,2}$, Amina Hamed Ahmed Alobaidi ${ }^{3}$ \\ ${ }^{1}$ Department of Medicine, Tikrit University College of Medicine, Tikrit Iraq, ${ }^{2}$ Department of Medicine, Faculty of Medicine, \\ Aalborg Academy of Science, Aalborg, Denmark, ${ }^{3}$ Department of Basic Sciences, Kirkuk University College of Veterinary \\ Medicine, Kirkuk, Iraq
}

Corresponding author: Prof. Abdulghani Mohamed Alsamarai, E-mail: galsamarrai@yahoo.com

\begin{abstract}
Background: Scabies is a common skin infection with worldwide distribution, mainly in developing countries. Aim: To estimate the frequency of scabies in displaced community. Methodology: The study was conducted in Kirkuk in a dermatology clinic during the period from $1^{\text {st }}$ of October 2015 to the end of October 2016. A total of 1639 subjects were included in the study, of them 860 (52.5\%) were male and 779 (47.5\%) were female, with age range from 1 month to 90 years for male, and 25 days to 80 years for female. Results: During the study period 153 scabies cases were identifies with overall incidence rate of $9.33 \%, 9.88 \%$ in male and $8.73 \%$ in female. The incidence was significantly higher $(12.2 \%)$ in subjects with age of $1-12$ years as compared to those with age of $\geq 13$ years $(8.03 \%)$. The majority of cases $(95.4 \%)$ were in displaced community. Conclusion: Scabies infestation in displaced communities is a public health problem with social and psychological impact on both displaced communities and Kirkuk city residents. Actions are needed to provide effective treatment and control.
\end{abstract}

Key words: Scabies; Displacement; Iraq, Kirkuk; Tikrit; Aalborg academy of science

\section{INTRODUCTION}

Skin diseases are common in Iraqi community, affecting both genders and all age groups [1-3]. Infections are the predominant etiology of dermatologic diseases and forming about $1 / 3$ of cases in different regional studies in Iraq [1-5]. Scabies is one of the skin infections with health impact and endemic worldwide, and with high burden in tropical countries [6]. However, the scabies prevalence with varied rate globally. Recent systematic review reported that scabies prevalence was with a range of $0.2 \%$ to $71.4 \%$, however, in the Middle East scabies prevalence was $<2.2 \%$ [7]. In Iraq, scabies prevalence was $3.3 \%$ in a community based study in Basrah, $1.2 \%$ in Tikrit, $1.9 \%$ in Samara, $2.7 \%$ in Kirkuk, $4.48 \%$ in Erbil $[1,4,5,8,9]$. However, in a study that was performed in Tikrit city during the period from $19^{\text {th }}$ May 2007 to $19^{\text {th }}$ February 2008, shows an increase in disease incidence (11.1\%) [10]. In addition, a study performed in Kerbela, Iraq, 2011, found that scabies incidence was $10.75 \%$ [11]. While Al-Musawi et al [12] reported incidence rate of $6.54 \%$ in Najaf for the year 2012. Furthermore, other study found that scabies incidence was $5.5 \%$ in Duhok, Northern of Iraq for the year 2014 [13]. This variability in scabies incidence/ prevalence rate may be due to that the studies are a mixture of outbreak studies or endemic disease status.

Unfortunately, scabies added to the WHO list of neglected disease in October, 2013 [14]. Many factors suggested influencing outbreaks and endemicity of scabies [15]; however, personal hygiene practice is associated with scabies infection [16]. In addition, scabies spread usually occurs during wars, floods, and earth quick [10].

Population displacement leads to a poor personal hygiene, low economic status, social stigma, unavailability of resources and health care delivery shortage. These conditions may attribute to outbreaks and endemicity of infectious diseases including scabies. Thus this study was conducted to estimate

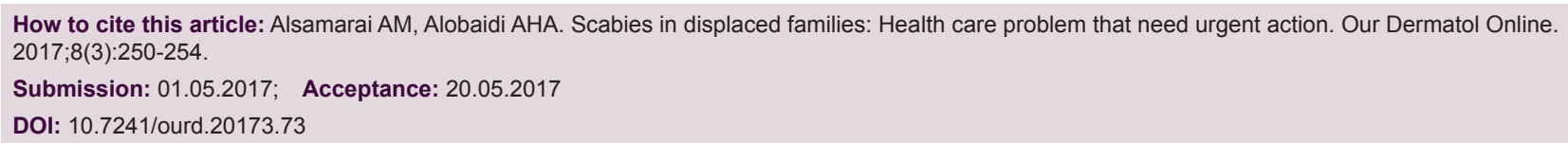


the frequency of scabies in a displaced population and propose a plan to overcome such challenge.

\section{MATERIAL AND METHODS}

The study was conducted in Kirkuk and included cases of scabies that was attended to a dermatology clinic in Hay Al-Askary. All patients attended to the dermatology clinic during the period from $1^{\text {st }}$ of October 2015 to the end of October 2016. A total of 1639 subjects were included in the study, of them $860(52.5 \%)$ were male and $779(47.5 \%)$ were female, with age range from 1 month to 90 years for male, and 25 days to 80 years for female. Cases of scabies were diagnosed according to conventional criteria [10].

\section{Statistical Analysis}

The frequency of scabies was presented as percent; while the age was presented as mean $[ \pm \mathrm{SD}]$. The significance of differences between mean values was determined using student t test, while between frequencies was determined using Ch square test. $\mathrm{P}$ value of $<0.05$ was considered as significant.

\section{RESULTS}

A total of 1639 subjects who presented to the clinic with complaints of skin diseases were included in the study. Scabies diagnosed in 153 (9.33\%) of cases, with a rate of $9.88 \%$ in male and $8.73 \%$ in female, with nonsignificant difference in relation to gender, Table 1.

The mean age of scabies cases subjects were $21.79 \pm 18.67$ years, with a non- significant difference between male $(22.23 \pm 16.23$ years $)$ and female (23.76 \pm 21.30 years), Table 2 .

Unfortunately, the frequency of scabies cases were more in both male (11.8\%) and female (12.6\%) in those with age of $1-12$ years as compared to subject as with $\geq 13$ years age, Table 3 . About 2/3 (66.7\%) of cases were of age $\leq 12$ years and women. This attributed to difficulty in achieving high cure rate; in addition, 95\% of cases were from displaced families and this lead to difficulty in control of the infection and high rate of treatment failure due to personal hygiene and cost of treatment that hurdle health care delivery.

The present study indicated that 153 households were infected with scabies. The Iraqi house hold size mean
Table 1: Scabies frequency

\begin{tabular}{lccc}
\hline Variable & Total number & $\begin{array}{c}\text { Number scabies } \\
\text { cases }\end{array}$ & $\begin{array}{c}\text { Percent scabies } \\
\text { cases }\end{array}$ \\
\hline Male & 860 & 85 & 9.88 \\
Female & 779 & 68 & 8.73 \\
$X^{2}$ & & 0.64 & \\
P value & 1639 & $>0.05$ & 9.33 \\
Total & 153 & \\
\hline
\end{tabular}

Table 2: Mean age of scabies cases

\begin{tabular}{lc}
\hline Variable & Mean age \pm SD \\
\hline Male & $22.23 \pm 16.23$ \\
Female & $23.76 \pm 21.30$ \\
$X^{2}$ & 0.50 \\
$P$ value & $>0.05$ \\
Total & $18.67 / 21.79$ \\
\hline
\end{tabular}

Table 3: Scabies frequency in subjects with age $\leq 12$ years

\begin{tabular}{|c|c|c|c|c|}
\hline \multirow[t]{3}{*}{ Variable } & \multicolumn{2}{|c|}{ Age in year } & \multirow[t]{3}{*}{$\mathbf{X}^{2}$} & \multirow[t]{3}{*}{$\mathbf{P}$} \\
\hline & \multicolumn{2}{|c|}{ No. cases/Total (\%) } & & \\
\hline & $1-12$ & 13 and above & & \\
\hline Male & $34 / 288(11.8)$ & $51 / 572(8.9)$ & 2.53 & $>0.05$ \\
\hline Female & 29/230 (12.6) & $39 / 549(7.1)$ & 6.17 & 0.013 \\
\hline$x^{2}$ & 0.77 & 1.25 & & \\
\hline$P$ value & $>0.05$ & $>0.05$ & & \\
\hline Total & $63 / 518$ (12.2) & $90 / 1121(8.03)$ & 7.15 & 0.007 \\
\hline
\end{tabular}

value was 7.7 (SASI 2006) and thus 1178 cases of scabies supposed to be present in these families.

\section{DISCUSSION}

This study shows that scabies frequency in a dermatologic clinic in Kirkuk was 9.33\%. This rate was higher than the previously reported studies for different geographical areas in Iraq, as show incidence rate with a range of $1.2 \%$ to $6.86 \%[3,4,5,8,9,11,12]$. However, one study [10] reported incidence rate of $11.1 \%$ in a dermatologic clinic and increased with time as previous studies show during the period from 1995 to 2005 . These studies show an incidence rate of $\leq 3.8 \%[1,3,4,5,8]$, while later studies reported incidence rate of $11.1 \%$ in Tikrit for the year 2009 [10], 6.86\% in Karbala for the year 2009-2010 [11], $6.54 \%$ in Najaf for the year 2012 [12], 5.5\% in Duhok for the years 2012-2013 [13], and 4.48 in Erbil for the year 2012 [9]. In addition, this study incidence rate is highhigher to that reported for Palestine (17/100 000) for the years 2005-2010 [17] and Turkey (1.5\%) for the year 2011 [18].

WHO review which included data of eighteen prevalence studies during the period from 1971 to 2001 reported that scabies prevalence range was $0.2 \%$ to $24 \%$ [19]. In the literature, high prevalence 
was reported for India, South Pacific and Northern Australia [15]. The prevalence was $70 \%$ in rural India, $50 \%$ in Australian Aboriginal communities and 18.5\% in Fiji children, 24\% in Vanuatu children, and 25\% in Solomon children [20-22]. The prevalence of scabies in developing countries during the period from 2005 to 2010 was $8.1 \%$ to $31 \%$ in Malaysia [23,24], $18.5 \%$ in Fiji [25], 17.3\% in Timor-Leste [26], 8.8\% -9.8\% in Brazil [27,28], 4.7\% in Nepal and Nigeria [29,30], and lowest prevalence was $0.4 \%$ in $4-6$ years children in Turkey [31].

Romani et al [7] in a recent review reported that overall quality of scabies studies was poor. The prevalence was $<10 \%$ for Europe and Middle East, while it was $>10 \%$ in other population studies included in the review, with a highest prevalence in Pacific and Latin America regions.

The incidence and prevalence of scabies was influenced by gender, age, overcrowding, ethnicity, season and personal hygiene [15]. Overcrowding, war time and climatic changes contributed to change in scabies prevalence from cyclical to epidemic pattern [32-36]. The increase in incidence of scabies in Iraq may be due to socio-economic status and behavioral factors that was an outcome of war, regional conflicts and displacement $[32,37,38]$.

Although, gender and age proposed as epidemiological factors that influence scabies prevalence [15], the present study not shows significant differences in scabies incidence in relation to gender and mean age of both male and female. This finding was not consistent with previous studies in Iraq that reveal significant differences in scabies incidence between male and female [10-12]. Although, there was no significant difference in scabies incidence between male and female, however, the incidence was higher in male $(9.88 \%)$ than that in female $(8.73 \%)$. Thus the incidence of scabies in female about the same to that reported for the year 2009 in Tikrit, but male incidence was lower to that in our previous study [10].

Sulaiman [9] in a hospital based study [HBS] in Erbil found higher incidence rate in female as compared to male. In contrast, Al-Hassan [11], in a HBS in Kerbela reported higher incidence of scabies in male $(8.5 \%)$ as compared to female $(4.7 \%)$. Other HBS reported that scabies incidence was more in male than in female [12]. The high incidence in male as compared to female in the above studies that were performed in Iraq may be due to that the main source of infection in their population study was the prison. Hay et al [15], suggest that scabies incidence rate was equal between genders and differences reported in literature may be due to confounding factors [37].

The mean age of subjects with scabies was 21.79 years indicating that scabies infection was more in younger age groups? This mean age of individuals with scabies about the of that reported before [10]. However, Al-Musawi et al [12] reported that mean age of subjects with scabies was 26.1 years, which is higher than that found in the present study.

Unfortunately, the present study shows that there was significantly higher scabies incidence in individuals with age of $1-12$ years $(12.2 \%)$ in both genders, than in those with age of $\geq 13$ years $(8.03 \%)$. However, this incidence rate was lower to that reported for 2009 in Tikrit [10]. Other studies in Iraq show that scabies incidence was higher in the age group 10-19 years in Najaf for the year 2012 [12], 21-50 years in Erbil for the year 2012 [9]. Al-Hassan [11] in Kerbela reported incidence rate of $6.7 \%$ in subjects with age of $<14$ years for the year 2009-2010. While Mero [13] reported incidence rate of $20.1 \%$ for the year 2012 2013 in subjects with age of 1-10 years in Duhok. In addition, Amro [17] found a significant higher scabies incidence in subjects with age of $\leq 10$ years for the years 2005-2010 in Palestine.

In developed countries scabies prevalence was similar across age groups [34], while in developing countries, the highest rate was in preschool children to adolescent [15]. Then scabies incidence declined in mid-adulthood and re-increase in the elderly [26,35]. Recent systematic review [7], found that scabies prevalence was higher in children than in adults and adolescents.

This study indicated that $95.4 \%$ of household with scabies infestation are displaced families and $66.7 \%$ of them were children $\leq 12$ years of age and women. This finding may lead to difficulty in treatment and control of scabies infestation.

The infected subjects from the 153 families may act as source of infection for their family members and thus the total number of infected individuals may reach 1178 cases. Thus presumably the total scabies cases in Kirkuk may be estimated as equal to 17670 cases, taking in consideration that there are 
15 dermatologic clinics in the city. This clarify that overall cases number represent health care problem because they act as focus for spread of scabies to Kirkuk residents and need urgent action to improve health care delivery to such community. The medical care supply by the International Organization for Migration (IOM) is not with effective covering which may be due to financial support and lack of professional health care providers.

The available drugs for scabies treatment in Iraq are permethrin and benzyl benzoate. Follow up of scabies cases demonstrated a high rate of disease spread to other family members, high rate of re-infection, and treatment failure. This was attributed to that household with scabies infestation are not able to get the sound treatment course for primary focus of the disease and other family members due to personal hygiene and economic status to get the suitable drugs and treatment course, these factors hurdle health care delivery. In such cases, the recommended treatment and control approach is the mass treatment. The best drug for mass treatment is ivermectin because it is easily administered to cases and not messy.

In conclusion, scabies infestation in displaced communities is a public health problem with social and psychological impact on both displaced communities and Kirkuk city residents. Actions are needed to provide effective treatment and control.

\section{Recommendation}

1. IOM and WHO should make an effort to establish a regional primary health care center in Kirkuk city for displaced families. Central Government support through the Ministry of Health and Ministry of Migration is vital action to consolidate the local government in Kirkuk to challenge the requirement of displaced communities.

2. The community leaders must play a role in funding the mass treatment programs.

\section{REFERENCES}

1. Al Samarai AM. Incidence of skin diseases in Samara, Iraq. Sci J Tikrit University 1995;1:53-60.

2. Al Saemarai AG. Prevalence of skin diseases in Iraq: a community based study. Int J Dermatol. 2009;48:734-9.

3. Alsamarai AGM. Prevalence of skin diseases in Samara, Iraq. Middle East J Internal Med. 2009;2:15-9.

4. Alaa NH. Epidemiology of skin diseases in Tikrit and Vicinity: a community based study. M Sc thesis. Tikrit University College of Medicine, 2002.
5. Murtada SH. Epidemiology of skin diseases in Kirkuk. M Sc thesis, Tikrit University College of Medicine, 2001.

6. Wendel K, Rompalo A. Scabies and pediculosis pubis: an update of treatment regimens and general review. Clin Infect Dis. 2002;35 Suppl 2:S146-51.

7. Romani L, Steer A, Whitefield MJ, Kaldor JM. Prevalence of scabies and impetigo worldwide: a systematic review. Lancet Infect Dis. 2015;15:960-67.

8. Al Rubaiy KK. Determinants and illness behavior of patients with skin diseases in Basrah Governorate. Ph D thesis. Basrah University College of Medicine, 2001.

9. Sulaiman AA. The frequency of scabies among patients attending the dermatology department in Erbil. MEJFM. 2013;11:38-42.

10. Alsamarai AGM. Frequency of scabies in Iraq: a survey in dermatologic clinic. J Infect Dev Ctries. 2009;3:789-3.

11. Al Hassan AT. The pattern of skin diseases in Karbala city: a retrospective study. QMJ. 2011;7:117-28.

12. Al-Musawi MM, Hasan HR, Maluki AH. Prevalence of scabies among patients attending the dermatology outpatient clinic in Najaf governorate, Iraq. J Adv Med Res. 2013;3:63-70.

13. Mero WM, Hassan HK. Incidence of human scabies in Duhok province, Kurdistan, Iraq. J Uni Zakho. 2014;2:285-92.

14. WHO. Scabies. Neglected tropical diseases. http//www.who.int/ neglected_diseases/diseases/scabies/en

15. Hay RJ, Steer AC, Engelman D, Walton S. Scabies in developing world- its prevalence, complications and management. Clin Microbial Infect. 2012;18:313-23.

16. Sianturi I, Sungkar S. The relationship between hygienic practices and scabies infestation in a boarding school in East Jakarta. Hubungan status Gizi dengan Gangguan Tiudur. 2014;2:91-5.

17. Amro A, Hamarshesh O. Epidemiology of scabies in west bank, Palestinian territories (occupied). Int J Infect Dis. 2012;16:e117-e20.

18. Bilgili ME, Yildiz H, Sarici G. Prevalence of skin diseases in a dermatology outpatient clinic in Turkey. A cross sectional, retrospective study. J Dermatol Case Rep. 2013;4:108-12.

19. World Health Organization. Epidemiology and management of common skin diseases in children in developing countries. Geneva, WHO, 2005.

20. Nair BK, Joseph A, Kandamuthan M. Epidemic scabies. Indian J Med Res. 1977;65:513-8.

21. Carapetis JR, Connors C, Yarmirr D, Krause V, Currie BJ. Success of a scabies control program in an Australian aboriginal community. Pediatr Infect Dis J. 1997;16:494-9.

22. Currie BJ, Connors CM, Krause VL. Scabies program s in aboriginal communities. Med J Aust. 1994;161:636-7.

23. Muhammad ZM, Saidatul SR, Adil AR, Rohela M, Jamaiah I. Prevalence of scabies and head lice among children in a welfare home in Palau Pinang, Malaysia. Trop Biomed. 2010;27:442-6.

24. Yap FBB, Elena E, Pabalan M. Prevalence of scabies and head lice among students of secondary boarding schools in Kuching, Sarawak, Malaysia. Pediatr Infect Dis J. 2010;29:682-3.

25. Steer AC, Jenney AW, Kado J, Batzloff MR, La Vincente S, Waqatakirewa L, et al. High burden lof impetigo and scabies in a tropical country. PloS Negl Trop Di.s 2009;3:e467.

26. dos Santos MM, Amaral S, Harmen SP, Joseph HM, Fernandes JL, Counahan ML. The prevalence of common skin infections in four districts in Timor-Leste: a cross sectional survey. BMC Infect Dis. 2010;10:61-6.

27. Heukelbach J, Wilcke T, Winter B, Feldmeier H. Epidemiology and morbidity of scabies and pediculosis capitis in resource-poor communities in Brazil. Br J Dermatol. 2005;153:150-6.

28. Feldmeier H, Jackson A, Ariza L, Calheiros CM, Soares Vde L, Oliveira FA, et al. The epidemiology of scabies in an impoverished community in rural Brazil: presence and severity of disease are associated with poor living conditions and illiteracy. J Am Acad Dermatol. 2009;60:436-43.

29. Walker SL, Shah M, Hubbard VG, Pradhan HM, Ghimire M. Skin 


\section{www.odermatol.com}

diseases is common in rural Nepal. results of a point prevalence study. Br J Dermatol. 2008;158:334-8.

30. Ogunbiyi AO, Owoaje E, Ndahi A. Prevalence of skin disorders in school children in Ibadan, Nigeria. Pediatr Dermatol. 2005;22:6-10.

31. Ciftci IH, Karaca S, Dogru O, Cetinkaya Z, Kulac M. Prevalence of pediculosis and scabies in preschool nursery children of Afyon, Tuekey. Korean J Parasitol. 2006;44:95-8.

32. Andrews JR. Scabies in New Zealand. Int J Dermatol. 1979;18:545-52.

33. Savin JA. Scabies in Edinburgh from 1815 to 2000. J R Soc Med. 2005;98:124-9.

34. Christophersen J. The epidemiology of scabies in Denmark, 1900 to 1975. Arch Dermatol. 1978;114:747-50

35. 13 Burkhart CG, Burkhart CN, Burkhart KM. An epidemiologic and therapeutic reassessment of scabies. Cutis. 2000;65:233-40.

36. 14 Mimouni D, Gdalevich M, Mimouni FB, Haviv J, Ashkenazi I.
The epidemiologic trends of scabies among Israeli soldiers: a 28 year follow-up. Int J Dermatol. 1998;37:586-7.

37. Burkhart CG. Scabies: an epidemiologic reassessment. Ann Intern Med. 1983;98:498-503.

38. Terry BC, Kanjah F, Sahr F, Kortequee S, Dukulay I, Gbakima AA. Sarcoptes scabiei infestation among children in a displacement camp in Sierra Leone. Public Health. 2001;115:208-11.

Copyright by Abdulghani Mohamed Alsamarai, et al. This is an open-access article distributed under the terms of the Creative Commons Attribution License, which permits unrestricted use, distribution, and reproduction in any medium, provided the original author and source are credited.

Source of Support: Nil, Conflict of Interest: None declared. 